\title{
PAPER
}

\section{Differentiation of dementia with Lewy bodies from Alzheimer's disease using a dopaminergic presynaptic ligand}

\author{
Z Walker, D C Costa, R W H Walker, K Shaw, S Gacinovic, T Stevens, G Livingston, \\ P Ince, I G McKeith, C L E Katona
}

See end of article for authors' affiliations

Correspondence to:

Dr Z Walker, St Margaret's Hospital, The Plain, Epping, Essex CM16 6TN,

UK; z.walker@ucl.ac.uk

Received 7 August 2001

In revised form

10 January 2002

Accepted

15 January 2002
J Neurol Neurosurg Psychiatry 2002;73:134-140

Background: Dementia with Lewy bodies (DLB) is one of the main differential diagnoses of Alzheimer's disease $(A D)$. Key pathological features of patients with DLB are not only the presence of cerebral cortical neuronal loss, with Lewy bodies in surviving neurones, but also loss of nigrostriatal dopaminergic neurones, similar to that of Parkinson's disease (PD). In DLB there is 40-70\% loss of striatal dopamine. Objective: To determine if detection of this dopaminergic degeneration can help to distinguish DLB from AD during life.

Methods: The integrity of the nigrostriatal metabolism in 27 patients with DLB, 17 with AD, 19 drug naive patients with PD, and 16 controls was assessed using a dopaminergic presynaptic ligand, ${ }^{123}$ labelled $2 \beta$-carbomethoxy-3 $\beta$-(4-iodophenyl)-N-(3-fluoropropyl)nortropane (FP-CIT), and single photon emission tomography (SPET). A SPET scan was carried out with a single slice, brain dedicated tomograph (SME 810 ) 3.5 hours after intravenous injection of $185 \mathrm{MBq}$ FP-CIT. With occipital cortex used as a radioactivity uptake reference, ratios for the caudate nucleus and the anterior and posterior putamen of both hemispheres were calculated. All scans were also rated by a simple visual method.

Results: Both DLB and PD patients had significantly lower uptake of radioactivity than patients with $A D$ $(p<0.001)$ and controls $(p<0.001)$ in the caudate nucleus and the anterior and posterior putamen. Conclusion: FP-CIT SPET provides a means of distinguishing DLB from AD during life.
D ementia with Lewy bodies (DLB) is the second most common type of degenerative dementia after Alzheimer's disease (AD).$^{1-3}$ The characteristic features of DLB are a progressive dementia with pronounced fluctuation in attention and levels of everyday activities, complex visual hallucinations, misperceptions, parkinsonism with frequent falls, and hypersensitivity to neuroleptic medication. As in $\mathrm{AD}$, a definitive diagnosis can only be made by histopathological examination of the brain. A clinical diagnosis is made on the basis of probabilities by considering the symptoms, results of investigations and neuropsychological tests, and, in a research setting, according to agreed diagnostic criteria. However, a large proportion of patients with the clinical diagnosis of DLB also fulfil the NINCDS-ADRDA criteria ${ }^{4}$ for AD.

To improve diagnostic accuracy during life, in 1995 a consortium on dementia with Lewy bodies established "Consensus clinical and pathological criteria for DLB". ${ }^{5}$ In a number of studies, the criteria were applied retrospectively to histopathologically confirmed cases of DLB. The specificity of the Consensus criteria has been reported to range from $29 \%$ to $100 \%$ and the sensitivity from $22 \%$ to $90 \% .^{6-12}$ Thus far there has only been one prospective study, ${ }^{13}$ in which the sensitivity of the Consensus criteria for DLB was $83 \%$ and the specificity was $95 \%$. Thus, at best, the Consensus criteria perform fairly well, particularly in specialised centres with an interest in DLB, and certainly no worse than diagnostic criteria for $\mathrm{AD}^{14}{ }^{15}$ or Parkinson's disease (PD), ${ }^{16}$ but nevertheless at least $15 \%$ of patients will continue to be misclassified.

There are a several reasons why it is important to separate DLB from other conditions during life. Patients with DLB warrant different management of their cognitive fluctuation, psychotic symptoms, and parkinsonian features. ${ }^{17}$ They have a worse prognosis if given neuroleptics, but respond well to cholinesterase inhibitors. ${ }^{18}$
The major neurochemical difference between $\mathrm{AD}$ and DLB is in the dopaminergic metabolism. Piggott $e t$ a $l^{19}$ studied postmortem brains from patients with PD, DLB, or AD, and elderly controls and showed that in DLB there is $72 \%$ reduction in the dopamine concentration in the putamen. This compares with $90 \%$ reduction in PD and no change in AD. In DLB, there is reduced binding to the dopamine uptake sites (presynaptic receptors) in the putamen (57\%), but again this is not as pronounced as in PD (75\%). There are no changes in uptake sites in $\mathrm{AD}$ compared with controls. The detection of this extensive dopaminergic degeneration would be expected to allow DLB to be distinguished from $\mathrm{AD}$ in vivo.

In DLB the loss of dopaminergic cells is accompanied by loss of the dopamine transporter (presynaptic receptors). This makes the dopamine transporter a surrogate marker for dopaminergic nigrostriatal neurones. Therefore, by imaging the dopamine transporter with single photon emission tomography (SPET), it is possible to assess the integrity of the nigrostriatal dopaminergic pathways.

Several ligands have been developed that have selective affinity for the dopamine transporter and can be used with SPET. The most promising SPET tracers for the dopamine transporter are cocaine analogues. A number of SPET studies in patients with $\mathrm{PD}$ have used the tracer ${ }^{123}$ I-labelled

Abbreviations: DLB, dementia with Lewy bodies; AD, Alzheimer's disease; PD, Parkinson's disease; SPET, single photon emission tomography; FP-CIT,

$2 \beta$-carbomethoxy-3 $\beta$-(4-iodophenyl)-N-(3-fluoropropyl)nortropane; MMSE mini mental state examination; CAMCOG, Cambridge cognitive function examination; $C D R$, clinical dementia rating; $B E H A V E-A D$, behavioural pathology in Alzheimer's disease; UPDRS, unified Parkinson's disease rating scale; H\&Y stage, Hoehn and Yahr stage; CAPE, Clifton assessment procedure for the elderly 

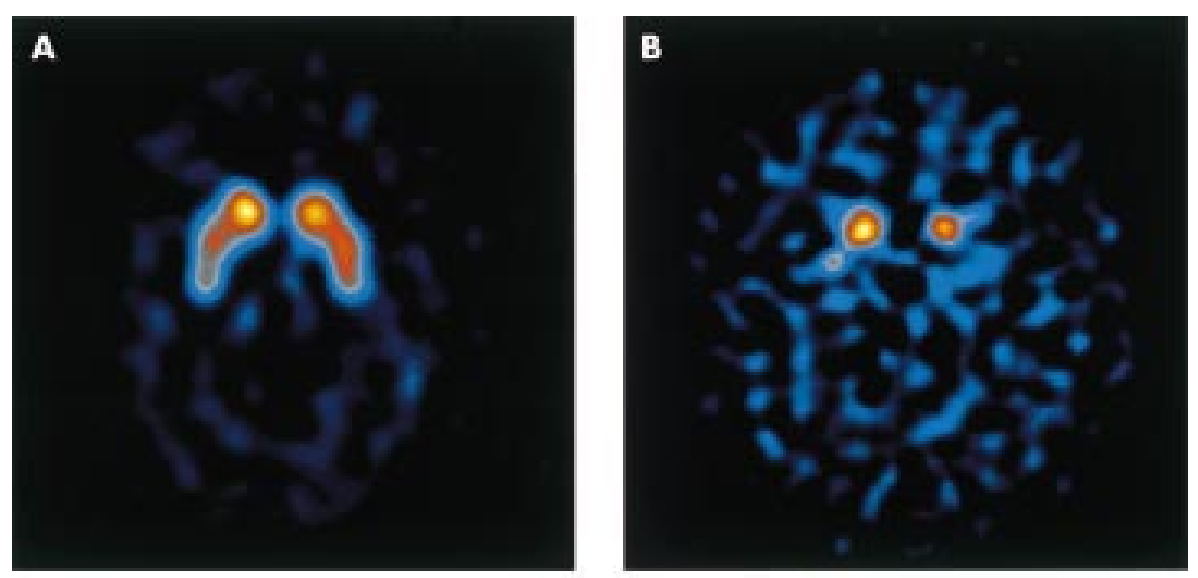

Figure 1 FP-CIT scans of a healthy control (A) and patients with (B) Parkinson's disease, (C) Alzheimer's disease, or (D) dementia with Lewy bodies.
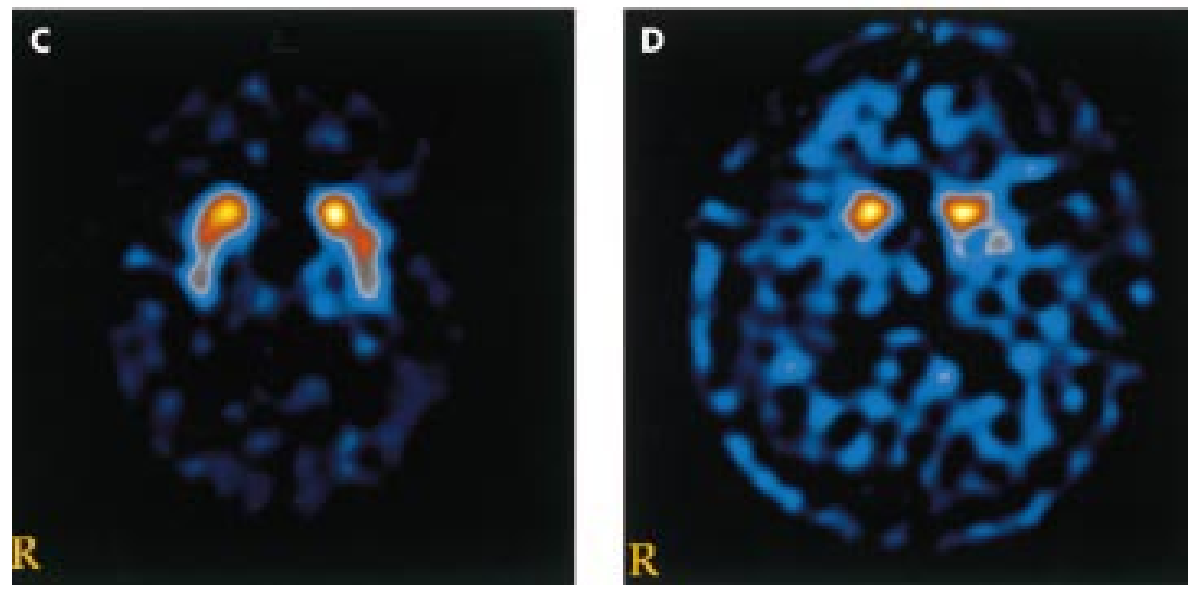

$2 \beta$-carbomethoxy-3 $\beta$-(4-iodophenyl)tropane ( $\beta$-CIT) to visualise the dopamine transporter. ${ }^{20-27}$ These studies showed a clear loss of striatal dopamine transporter in patients with PD compared with controls.

Important findings that bear on the usefulness of $\beta$-CIT in differentiating DLB from AD come from studies of patients with hemiparkinsonism. Marek et $a l^{28}$ showed that, in patients with hemiparkinsonism, striatal uptake was substantially reduced in the contralateral side (by 53\%) but also in the ipsilateral side (by $38 \%$ ). Similar results were obtained by Brucke et al. ${ }^{29}$ Thus a deficit in dopamine transporter, and therefore loss of dopaminergic neurones, can be shown with $\beta$-CIT at a time when no clinical signs are apparent. One would therefore expect that $\beta$-CIT SPET would detect the striatal dopaminergic deficit in patients with DLB. Donnemiller et $a l^{30}$ performed $\beta$-CIT SPET on seven patients with DLB, six patients with AD, and three controls. Uptake of radioactivity in the striatum was not significantly different in patients with $\mathrm{AD}$ and controls. Patients with DLB had significantly lower uptake than both controls and patients with AD. $\beta$-CIT does, however, have a significant drawback: its uptake in the human striatum is characterised by very slow kinetics. A stable level of striatal radioactivity (equilibrium of specific to non-specific uptake of radioactivity) is only achieved $20-30$ hours after injection. ${ }^{31}$ This means that adequate images can only be acquired a day after injection of the ligand, and this diminishes its usefulness for outpatients.

Recently a new ligand, ${ }^{123}$ I-labelled $2 \beta$-carbomethoxy-3 $\beta$-(4iodophenyl)-N-(3-fluoropropyl)nortropane (FP-CIT), has become available. As with $\beta$-CIT, in patients with PD there is bilateral reduction of striatal uptake of FP-CIT. ${ }^{32-34}$ FP-CIT is taken up more rapidly in the human striatum than $\beta$-CIT. The practical clinical advantage of the fast kinetics of FP-CIT is that patients can be scanned on the same day three to six hours after injection.
Our hypothesis was that patients with DLB (and those with PD) will have significantly lower uptake of FP-CIT (reflecting neuronal loss) than patients with $\mathrm{AD}$ and controls.

\section{METHODS}

\section{Patients}

Patients were recruited from the Derwent Memory Clinic, the old age psychiatry and neurology outpatient clinics, and hospital wards at Princess Alexandra Hospital, Harlow, St Margaret's Hospital, Epping, and the Whittington Hospital, London. Healthy elderly controls were recruited from relatives and partners of patients (mainly spouses). Controls were not taking any drugs known to affect the dopaminergic system. Dementia was diagnosed clinically. Patients were ascribed to either the DLB or the AD group by fulfilling the Consensus DLB criteria ${ }^{5}$ or NINCDS-ADRDA criteria. ${ }^{4}$ Many of the patients with DLB fulfilled both sets of criteria, and these patients were classified as having DLB. The diagnosis of PD was made according to the UK Parkinson's Disease Society Brain Bank criteria. ${ }^{16}$ Patients with PD were recruited from a neurology clinic at the time of first presentation to a neurologist (RWHW) and had not been exposed to any antiparkinsonian medication at the time of scanning. Neuropathological diagnosis was made as described by McKeith et al. ${ }^{13}$

\section{Assessment}

\section{Patients with $A D$ or DLB}

For each patient a detailed history of memory impairment from the patient and an informant was obtained. This was followed by a full psychiatric history, a mental state examination, and a physical examination with an emphasis on neurological examination. A number of tests were performed:

- the mini mental state examination (MMSE; adapted from Folstein $e t \mathrm{l}^{35}$ ); 


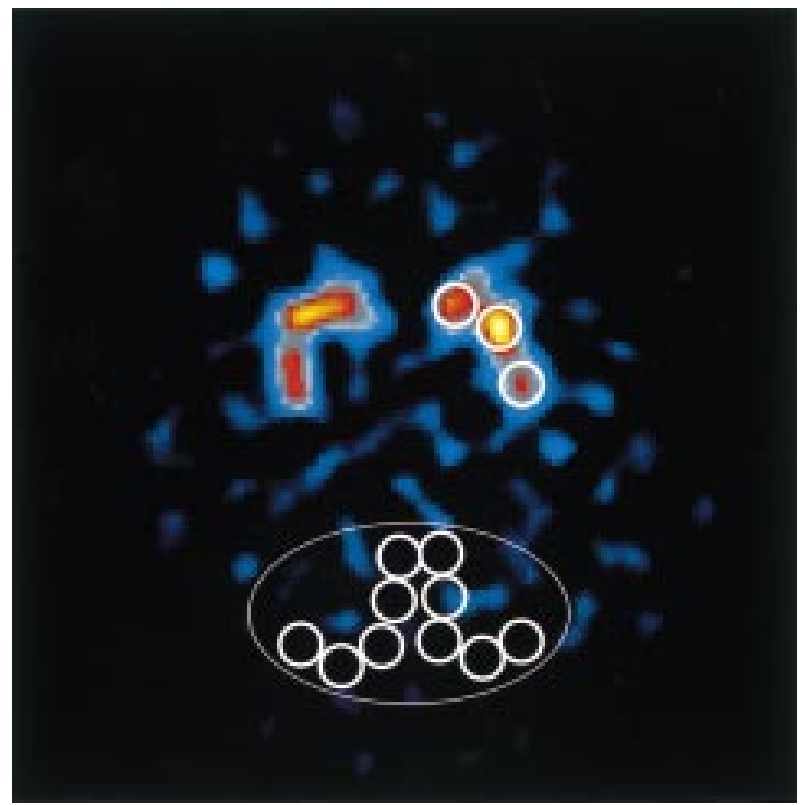

Figure 2 FP-CIT scan showing regions of interest in the caudate nucleus, anterior and posterior putamen, and occipital cortex.

- the Cambridge cognitive function examination (CAMCOG), a neuropsychological test battery which forms part of a standardised psychiatric assessment schedule, the Cambridge mental disorders of the elderly examination (CAMDEX) $)^{36}$;

- the clinical dementia rating $(\mathrm{CDR})^{37}$;

- the Cornell scale for depression in dementia (Cornell depression scale) $)^{38}$;

- the behavioural pathology in Alzheimer's disease rating scale (BEHAVE-AD) ${ }^{39}$;

- the unified Parkinson's disease rating scale, motor part only $(\mathrm{UPDRS})^{40}$;

- the Hoehn and Yahr stage (H\&Y stage) ${ }^{41}$;

- the Clifton assessment procedure for the elderly, behavioural rating scale only (CAPE). ${ }^{42}$

\section{Investigations}

The following investigations were arranged for all patients if not already performed by a referring doctor: full blood count, erythrocyte sedimentation rate, urea and electrolytes, glucose, liver function tests, $\mathrm{Ca}^{2+}$, thyroid function test and syphilis serology, VDRL, vitamin B12, folate, and magnetic resonance imaging or computed tomography brain scan.

\section{Patients with PD}

Tests performed were: MMSE, CAMCOG, CDR, UPDRS, and H\&Y stage.

\section{Controls}

Information was gathered from controls about their medical and psychiatric history and any regular medication. A mental state examination and a limited physical examination were carried out. Tests performed were: MMSE, CAMCOG, UPDRS, and H\&Y stage.

\section{FP-CIT SPET scan}

SPET studies were carried out at the Institute of Nuclear Medicine, University College London Medical School. Thyroid metabolism was blocked with potassium iodate, as recommended, to reduce possible irradiation of the gland.

All subjects were scanned with a brain dedicated scanner, the Strichman Medical Equipment 810 linked to a Macintosh
Table 1 Cohort characteristics of patients with dementia with Lewy bodies (DLB) or Alzheimer's disease (AD)

\begin{tabular}{|c|c|c|c|}
\hline Characteristic & $\begin{array}{l}\text { DLB } \\
(n=27)\end{array}$ & $\begin{array}{l}A D \\
(n=17)\end{array}$ & Significance \\
\hline \multicolumn{4}{|c|}{ Positive family history of PD } \\
\hline Yes & $22 \%$ & $6 \%$ & NS \\
\hline \multicolumn{4}{|c|}{ Positive family history of dementia } \\
\hline Yes & $33 \%$ & $35 \%$ & NS \\
\hline \multicolumn{4}{|c|}{ Past psychiatric history } \\
\hline Yes & $19 \%$ & $24 \%$ & NS \\
\hline \multicolumn{4}{|c|}{ Alcohol coNSumption } \\
\hline Moderate & $56 \%$ & $70 \%$ & NS \\
\hline Excessive & $4 \%$ & $6 \%$ & \\
\hline \multicolumn{4}{|c|}{ History of smoking } \\
\hline Smoker & $4 \%$ & $12 \%$ & NS \\
\hline Ex-smoker & $11 \%$ & $18 \%$ & \\
\hline \multicolumn{4}{|c|}{ Fluctuating course of illness } \\
\hline Yes & $85 \%$ & $12 \%$ & $p<0.001$ \\
\hline \multicolumn{4}{|c|}{ Acute confusional states } \\
\hline Yes & $22 \%$ & $12 \%$ & NS \\
\hline \multicolumn{4}{|c|}{ Visual hallucinatioNS } \\
\hline Once only & $26 \%$ & $6 \%$ & $p<0.001$ \\
\hline Persistent & $67 \%$ & $0 \%$ & \\
\hline \multicolumn{4}{|l|}{ Tremor } \\
\hline Yes & $59 \%$ & $24 \%$ & $p<0.03$ \\
\hline \multicolumn{4}{|l|}{ Rigidity } \\
\hline \multirow{2}{*}{\multicolumn{4}{|c|}{ Akinesia/bradykinesia }} \\
\hline & & & \\
\hline Yes & $67 \%$ & $18 \%$ & $p<0.01$ \\
\hline
\end{tabular}

computer. The Strichman camera consists of 12 individual detectors, each equipped with a focusing collimator. The transaxial resolution of this camera is $7.6 \mathrm{~mm}$ full width half maximum, and axial resolution is $12.5 \mathrm{~mm}$. The measured concentration of radioactivity was expressed as Strichman medical units (SMUs; I SMU $=100 \mathrm{~Bq} / \mathrm{ml}$ ). Scanning took place between three and four hours after injection of FP-CIT (185 MBq). Usually 8-10 slices were acquired starting at the cerebellum level upwards to include basal ganglia. A few patients were difficult to scan, and, in these, a smaller number of slices (three to five) were acquired at the level of the basal ganglia to include the entire basal ganglion region. The overall scanning time for each patient was 30-45 minutes.

All scans were analysed by DCC, who was unaware of the diagnostic status of the subjects. The images were automatically reconstructed. For analysis of striatal binding, the ratio of specific to non-specific binding was calculated by summing up two to three adjacent transverse slices that showed the most intense striatal uptake. Regular circular regions of interest were used to calculate the average striatal (caudate nucleus, anterior and posterior putamen) to non-specific (areas with little or no dopamine receptors, such as occipital lobes) radioactivity ratios for both hemispheres (figs 1 and 2). The formula used was:

\section{FP-CIT binding $=$ STR $/ O C C$}

where STR is the mean radioactivity (in SMUs) in the striatum (caudate, anterior and posterior putamen) and OCC is the mean radioactivity in the occipital cortex.

\section{Visual rating of scans}

As a separate exercise, all the scans were presented randomly and assessed visually, purely qualitatively, by three independent raters (DCC, ZW, and RWHW) who were blind to the clinical and autopsy diagnoses. Scans were scored as follows: 0, normal uptake in all regions (right and left caudate and whole putamen); 1 , slight reduction in uptake in any of the four regions; 2 , significant reduction in uptake in any of the four regions. Subsequently for all correlations and statistical 
Table 2 Cohort characteristics of patients with dementia with Lewy bodies (DLB), Alzheimer's disease (AD), or Parkinson's disease (PD), and controls

\begin{tabular}{|c|c|c|c|c|}
\hline Characteristic & DLB $(n=27)$ & $A D(n=17)$ & $P D(n=19)$ & Controls $(n=16)$ \\
\hline \multicolumn{5}{|l|}{ Sex ratio } \\
\hline$M: F$ & $10: 17$ & $9: 8$ & $15: 4$ & 10:6 \\
\hline \multicolumn{5}{|c|}{ Age at time of FP-CIT } \\
\hline Mean (SD) & $77.3(7.9)$ & $78.0(7.2)$ & $64.9(9.1)$ & $66.6(10.8)$ \\
\hline Median & 77 & 77 & 62 & 70 \\
\hline \multicolumn{5}{|c|}{ Age at onset of dementia } \\
\hline Mean (SD) & $73.1(8.0)$ & $73.1(6.8)$ & & \\
\hline Median & 73 & 73 & & \\
\hline \multicolumn{5}{|l|}{ Systolic pressure } \\
\hline Mean (SD) & $138.4(28.6)$ & $140.1(24.4)$ & $149.6(23.9)$ & \\
\hline Median & 135 & 140 & 143 & \\
\hline \multicolumn{5}{|c|}{ Years of education } \\
\hline Mean (SD) & $9.7(1.9)$ & $9.3(1.5)$ & $10.6(2.7)$ & $11.9(3.4)$ \\
\hline Median & 9 & 9 & 10 & 11 \\
\hline \multicolumn{5}{|l|}{$H \& Y$ staging } \\
\hline Mean (SD) & $2.2(1.2)$ & $0.3(0.8)$ & $1.7(0.6)$ & $0.1(0.2)$ \\
\hline Median & 2 & 0 & 1.5 & 0 \\
\hline \multicolumn{5}{|l|}{ UPDRS score } \\
\hline Mean (SD) & $18.0(11.2)$ & $3.1(5.0)$ & $14.8(4.9)$ & $2.2(3.5)$ \\
\hline Median & 18 & 1 & 16 & 1 \\
\hline
\end{tabular}

FP-CIT, $2 \beta$-carbomethoxy-3 $\beta$-(4-iodophenyl)-N-(3-fluoropropyl)nortropane; UPDRS, unified Parkinson's disease rating scale; H\&Y stage, Hoehn and Yahr stage.

analyses, scans with scores of 0 or 1 were combined into a "normal" group and scans with a score of 2 were declared "abnormal".

\section{Statistical analysis}

Data were analysed using SPSS/PC + version 10.0 (Statistical Package for Social Sciences). FP-CIT binding was calculated for caudate, anterior and posterior putamen separately for each hemisphere. For patients with PD, "contralateral side" was defined as the side opposite to the clinically worse affected side. For patients with DLB or AD, it was difficult clinically to decide which side should be taken as the more affected, as some patients did not have any extrapyramidal signs, and therefore contralateral was arbitrarily assigned to the left side and ipsilateral to the right side. Analysis of variance and the $t$ test were used to assess differences between the four groups (DLB, AD, PD, and controls) in ipsilateral and contralateral FP-CIT binding in the caudate and anterior and posterior putamen and between the four groups and their basic indices (age, MMSE, CAMCOG, CDR, BEHAVE-AD, UPDRS, Cornell depression scale, and CAPE). Cohen's $\kappa$ test was used for inter-rater reliability.

\section{Ethical approval}

Ethical approval was obtained from West Essex Health Authority ethics committee, the Camden and Islington NHS Community Trust ethics committee, and the Administration of Radioactive Substances advisory committee of the United Kingdom.

\section{RESULTS}

As classified using clinical criteria, there were 27 patients with DLB, 17 patients with $\mathrm{AD}, 19$ patients with $\mathrm{PD}$, and 16 controls.

\section{Basic characteristics of the cohort}

Table 1 shows the frequency in patients with DLB or AD of: a family history of PD or AD; past psychiatric history; alcohol consumption; history of smoking; fluctuating course of illness, acute confusional states, visual hallucinations; tremor; rigidity; akinesia/bradykinesia. There was no significant difference between the two patient groups with respect to sex, the age at time of scan, age at onset of dementia, systolic blood pressure, and years of education (table 2).
There were differences between patients with DLB and those with $\mathrm{AD}$ on the CDR, the MMSE, and the CAMCOG scores, the former being more severely demented. The Cornell depression scale scores were slightly higher for DLB than AD, but in neither group were they in the range indicating severe depression. Patients with DLB scored significantly worse (higher score) on CAPE and BEHAVE-AD than patients with $\mathrm{AD}$ (table 3).

Patients with PD and controls were significantly younger than patients with DLB $(\mathrm{p}<0.01)$ and scored higher on the MMSE (MMSE mean DLB 16.2, AD $21.5 v$ PD 27.7, controls 28.9; $\mathrm{p}<0.001$ ) and the CAMCOG (DLB 49.3, AD $69.8 v$ PD 98.8, controls 101.5; $\mathrm{p}<0.001$ ).

As expected, both PD and DLB patients scored higher on the UPDRS and the HEY stage than did patients with AD and controls (table $2 ; \mathrm{p}<0.001$ ).

Table 3 Ratings of patients with dementia with Lewy bodies (DLB) or Alzheimer's disease (AD)

\begin{tabular}{|c|c|c|c|}
\hline Scale & DLB $(n=27)$ & $A D(n=17)$ & $\mathrm{p}$ Value \\
\hline \multicolumn{4}{|l|}{ CDR } \\
\hline Mean (SD) & $1.6(0.82)$ & $0.94(0.48)$ & $<0.01$ \\
\hline Median & 2.0 & 1.0 & \\
\hline \multicolumn{4}{|l|}{ MMSE } \\
\hline Mean (SD) & $16.2(6.2)$ & $21.5(5.3)$ & $<0.01$ \\
\hline Median & 17 & 23 & \\
\hline \multicolumn{4}{|l|}{ CAMCOG } \\
\hline Mean (SD) & $49.3(26.0)$ & $69.8(15.2)$ & $<0.01$ \\
\hline Median & 58 & 73 & \\
\hline \multicolumn{4}{|c|}{ Cornell scale for depression in dementia } \\
\hline Mean (SD) & $6.7(5.4)$ & $3.5(3.5)$ & $<0.05$ \\
\hline Median & 6 & 3 & \\
\hline \multicolumn{4}{|l|}{ BEHAVE-AD } \\
\hline Mean (SD) & $10.0(5.9)$ & $3.1(4.5)$ & $<0.001$ \\
\hline Median & 9 & 1 & \\
\hline \multicolumn{4}{|l|}{ CAPE } \\
\hline Mean (SD) & $12.4(7.6)$ & $4.9(5.0)$ & $<0.001$ \\
\hline Median & & 2 & \\
\hline
\end{tabular}

CDR, Clinical dementia rating; MMSE, mini mental state examination; CAMCOG, Cambridge cognitive function examination; BEHAVE-AD, behavioural pathology in Alzheimer's disease; CAPE, Clifton assessment procedure for the elderly. 
Table 4 Semiquantitative FP-CIT binding measures

\begin{tabular}{|c|c|c|c|c|}
\hline Binding & DLB $(n=27)$ & $A D(n=17)$ & $P D(n=19)$ & Controls $(n=16)$ \\
\hline \multirow[t]{2}{*}{ Ipsilateral caudate } & 3.91 & 5.39 & 4.55 & 5.85 \\
\hline & 3.52 to 4.30 & 4.90 to 5.87 & 4.28 to 4.82 & 5.30 to 6.40 \\
\hline Contralateral & 3.97 & 5.65 & 4.57 & 6.02 \\
\hline caudate & 3.50 to 4.43 & 5.22 to 6.07 & 4.16 to 4.98 & 5.52 to 6.53 \\
\hline Ipsilateral anterior & 3.31 & 4.91 & 3.49 & 5.19 \\
\hline putamen & 2.90 to 3.73 & 4.47 to 5.35 & 3.05 to 3.93 & 4.72 to 5.67 \\
\hline Contralateral anterior & 3.44 & 5.10 & 3.27 & 5.14 \\
\hline putamen & 3.04 to 3.84 & 4.62 to 5.57 & 2.75 to 3.78 & 4.62 to 5.66 \\
\hline Ipsilateral posterior & 3.06 & 4.11 & 2.53 & 4.44 \\
\hline putamen & 2.63 to 3.50 & 3.72 to 4.49 & 2.31 to 2.76 & 3.99 to 4.87 \\
\hline Contralateral posterior & 2.95 & 3.96 & 2.14 & 4.43 \\
\hline putamen & 2.56 to 3.33 & 3.71 to 4.21 & 1.9 to 2.36 & 4.05 to 4.81 \\
\hline
\end{tabular}

\section{Binding of FP-CIT radioactivity (semiquantitative method)}

Table 4 and figs 3, 4, and 5 show the mean contralateral and ipsilateral radioactivity binding in the caudate nucleus and the anterior and posterior putamen in the four groups. Both the DLB and PD groups showed significantly lower uptake of radioactivity in all striatal areas than the $\mathrm{AD}$ group and controls (analysis of variance: $\mathrm{p}<0.001$, in the contralateral and the ipsilateral caudate nucleus and anterior and posterior putamen). There were highly significant differences between DLB and AD, and DLB and controls for all ipsilateral and contralateral binding measures ( $t$ tests; $\mathrm{p}<0.001$ ). There was a clear separation of the AD and DLB groups with no overlap of the $95 \%$ confidence intervals for the means of radioactivity binding. There were no significant differences in binding measures between patients with $\mathrm{AD}$ and controls in the ipsilateral and the contralateral caudate, the ipsilateral and the contralateral anterior putamen, and the ipsilateral posterior putamen, but patients with $\mathrm{AD}$ had lower binding than controls in the contralateral posterior putamen $(\mathrm{p}<0.05)$

There were highly significant differences in all binding measures between PD and controls $(\mathrm{p}<0.001)$ and between $\mathrm{PD}$ and $\mathrm{AD}(\mathrm{p}<0.005)$.

\section{Simple qualitative visual assessment of scans}

There was excellent agreement between the independent assessments of the specialist in nuclear medicine, the old age psychiatrist, and the neurologist ( $\kappa$ values $0.85,0.89,0.9$ ). We compared the visual rating with the semiquantitative results by defining as abnormal any scan with contralateral posterior putamen binding that was more than 2 SDs below the mean of the controls $(<3.02)$. The consensus visual rating (two or all three assessments in agreement) and the semiquantitative rating gave the same result (normal or abnormal scan) in $72 / 79$ scans $(91 \%)$, with $\kappa 0.82$, again an excellent agreement.

\section{Autopsies}

To date we have results of autopsies on 10 of the patients with dementia (table 5). These highlight shortcomings in the accuracy of the diagnoses made using the clinical diagnostic criteria, with an apparent tendency to overdiagnose DLB. The autopsy data have a number of effects on the results reported above. Reanalysing the data in the light of autopsy diagnoses where available, there are no longer significant differences between the DLB and AD groups with respect to: MMSE,
CAMCOG, CDR, Cornell depression scale, BEHAVE-AD, and CAPE. The confidence intervals for the semiquantitative binding measures for the DLB group are all somewhat narrower, and importantly the separation of the DLB group from the $\mathrm{AD}$ group becomes greater (data not shown). Most importantly, with one exception (case 5), an abnormal scan always associates with an autopsy diagnosis of DLB, giving a sensitivity of $100 \%$ and a specificity of $83 \%$, in comparison with high sensitivity but very low specificity for the clinical Consensus criteria for DLB in our clinics. In case 5, the explanation for the misleading scan is that the autopsy showed an infarct in the putamen on the side with low ligand binding, and in fact the binding values in the five other regions of that scan were well maintained, arguing in retrospect against a nigrostriatal degenerative process.

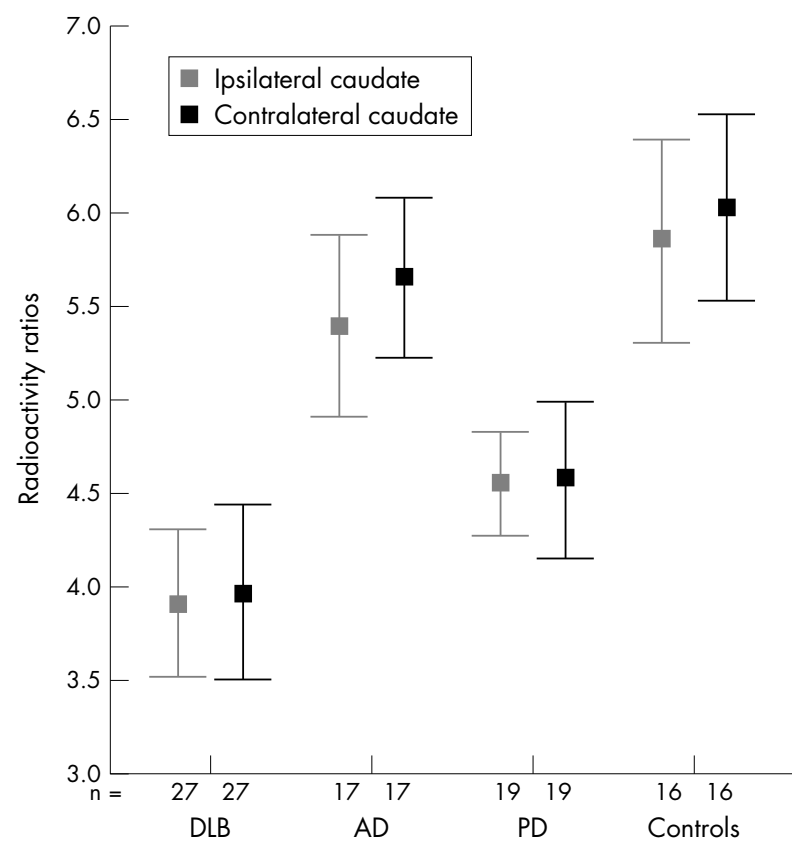

Figure 3 Radioactivity ratios in the caudate nucleus for patients with dementia with Lewy bodies (DLB), Alzheimer's disease (AD), or Parkinson's disease (PD) and healthy controls. Means and 95\% confidence intervals are shown. 


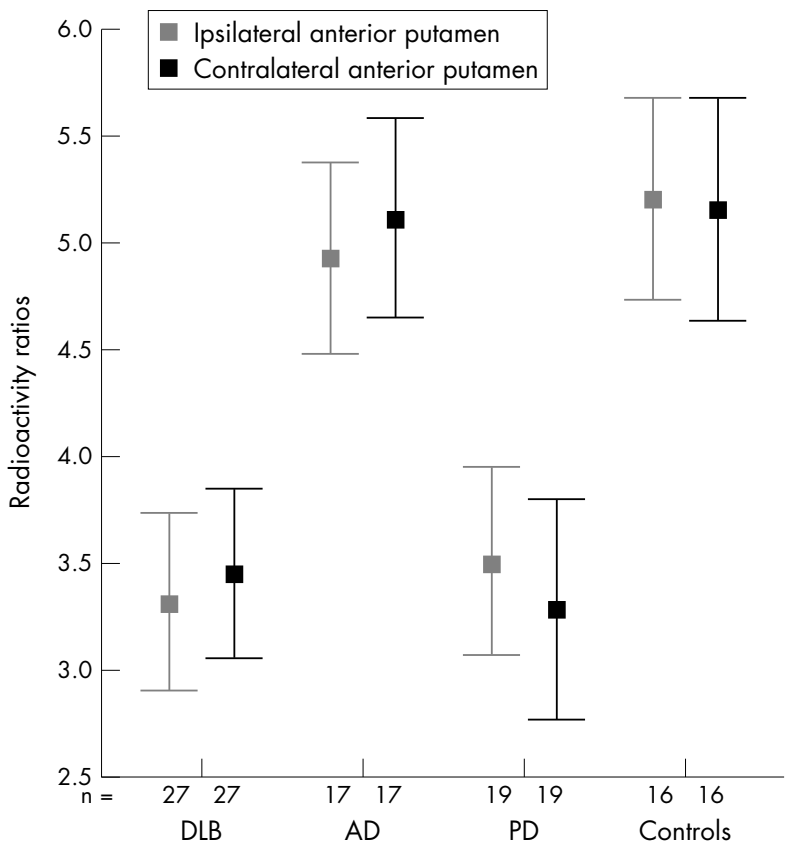

Figure 4 Radioactivity ratios in the anterior putamen for patients with dementia with Lewy bodies (DLB), Alzheimer's disease (AD), or Parkinson's disease (PD) and healthy controls. Means and 95\% confidence intervals are shown.

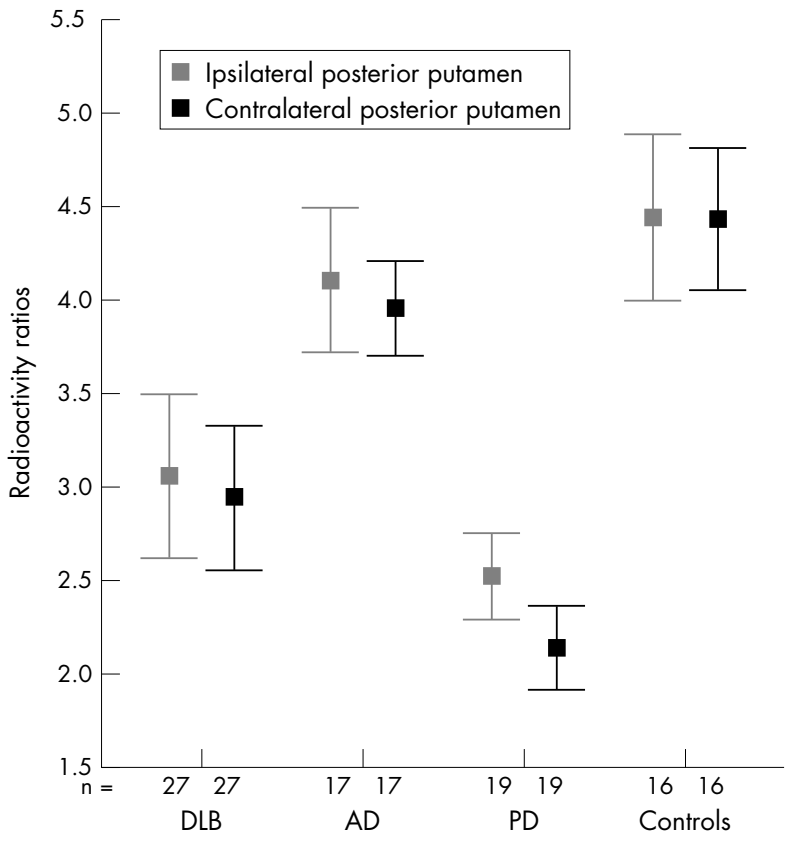

Figure 5 Radioactivity ratios in the posterior putamen for patients with dementia with Lewy bodies (DLB), Alzheimer's disease (AD), or Parkinson's disease (PD) and healthy controls. Means and 95\% confidence intervals are shown.

\section{DISCUSSION}

This study shows that FP-CIT SPET clearly distinguishes a group of clinically classified patients with $\mathrm{AD}$ from a group of clinically classified patients with DLB. Furthermore, in this series, on the basis of final diagnoses made at autopsy, FP-CIT SPET scans performed better than clinical criteria in supporting the diagnosis of DLB in patients with dementia. The implication is that the use of FP-CIT SPET would improve the accuracy of diagnosis of DLB during life. Importantly, FP-CIT
Table 5 Comparison of clinical diagnosis, FP-CIT scan result, and autopsy in the 10 patients for whom autopsies have become available

\begin{tabular}{|c|c|c|c|}
\hline Case & $\begin{array}{l}\text { Clinical } \\
\text { diagnosis }\end{array}$ & Scan result & $\begin{array}{l}\text { Autopsy } \\
\text { diagnosis }\end{array}$ \\
\hline 1 & DLB & Abnormal & DLB \\
\hline 2 & DLB & Abnormal & DLB \\
\hline 3 & DLB & Abnormal & DLB \\
\hline 4 & DLB & Abnormal & DLB \\
\hline 5 & DLB & Abnormal & $\mathrm{AD} / \mathrm{VaD}$ \\
\hline 6 & DLB & Normal & CBD \\
\hline 7 & DLB & Normal & $A D$ \\
\hline 8 & DLB & Normal & $A D$ \\
\hline 9 & DLB & Normal & $A D$ \\
\hline 10 & $A D$ & Normal & $A D$ \\
\hline
\end{tabular}

SPET could only be expected to support a clinical diagnosis, because any dementia that also involves nigrostriatal pathology, such as corticobasal degeneration or frontotemporal dementia with parkinsonism, or mixed pathology, may give rise to an abnormal FP-CIT SPET result, as indeed the case of putamen infarction in this study showed. Our patient with corticobasal degeneration had a scan that was "mildly abnormal" on visual inspection, but the posterior putamen binding was not in the abnormal range as we defined it.

This is the first study to show that it is possible to detect a clear reduction in striatal dopamine transporter in patients with DLB using FP-CIT SPET. It extends the observation by Donnemiller $e t \mathrm{l}^{30}$ that patients with "diffuse Lewy body dis-

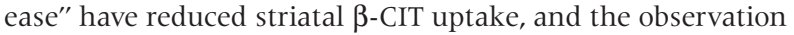
by $\mathrm{Hu}$ et $\mathrm{al}^{43}$ using photon emission tomography that patients with DLB who have extrapyramidal signs and are responsive to L-dopa have significantly reduced uptake of ${ }^{18} \mathrm{~F}$-flurodopa in the putamen and the caudate nuclei. Our findings agree with autopsy studies of DLB that show loss of neurones in the substantia nigra with concomitant reduction in dopamine reuptake sites and dopamine levels in the striatum. ${ }^{19}{ }^{44}$

SPET scanning with FP-CIT appears to be clinically feasible. The scanning procedure was well tolerated by patients and controls. It was possible to obtain a good quality scan for all participants of the study, and no serious adverse effects were observed. The only possible adverse effect was that on one occasion a patient was incontinent during the scanning procedure.

The data show that simple visual rating of scans is effective, although we consider that the semiquantitative analysis of scans considerably enhances the information that can be obtained from them.

There were no significant differences in binding measures between patients with $\mathrm{AD}$ and controls apart from in the contralateral posterior putamen, where patients with AD had $10 \%$ lower counts than controls. Lavalaye et $a l^{45}$ have shown that the density of dopamine transporter declines with age, with a decrease in FP-CIT binding in the striatum of about $4 \%$ per decade. The healthy controls were about 10 years younger than the patients with $\mathrm{AD}$ and DLB, and the age difference may explain the slightly lower counts in patients with AD. It is also possible that some of the patients assigned clinically to the AD group actually have DLB.

Although other groups have reported good sensitivity and specificity for the Consensus criteria for DLB, ${ }^{611-13}$ their diagnostic accuracy in the present study has so far been disappointing; the reason for the lower specificity is not clear. It may simply be a chance phenomenon, and the numbers of cases are small (the specificity was $100 \%$ in a previous small 
series from our group $\left.{ }^{46}\right)$. The fact that all cases that fulfilled both AD and DLB diagnostic criteria were classified as DLB is also relevant. Nevertheless, the study reported here suggests that the incorporation of the results of functional imaging of the striatum into diagnostic criteria would greatly improve the precision of diagnosis of DLB during life.

\section{ACKNOWLEDGEMENTS}

We are grateful to the patients and their relatives who took part in the study. We also thank Mr Kenneth Connolly from the pathology department at Princess Alexandra Hospital and Dr Evelyn Jaros, Professor Robert Perry, and Ms Jean Dawes from the MRC Neuropathology Unit in Newcastle. The work was supported by grants from Nycomed Amersham plc, UK and Novartis.

\section{Authors' affiliations}

Z Walker, D C Costa, K Shaw, S Gacinovic, T Stevens, G Livingston, C L E Katona, University College London, London, UK R W H Walker, Barts and The London NHS Trust, London

$P$ Ince, University of Sheffield, Sheffield, UK

I G McKeith, Institute for the Ageing and Health, University of Newcastle upon Tyne, Newcastle upon Tyne, UK

Competing interests: DCC received some financial support from Nycomed Amersham plc, now called Amersham Healthcare. IGMcK has received consultancy fees and research funds from Nycomed Amersham plc. ZW has received research funds from Nycomed Amersham plc.

\section{REFERENCES}

1 Perry RH, Irving D, Blessed G, et al. Senile dementia of Lewy body type: a clinically and neuropathologically distinct form of Lewy body dementia in the elderly. J Neurol Sci 1990;95:1 19-39.

2 Hansen L, Salmon D, Galasko D, et al. The Lewy body variant of Alzheimer's disease: a clinical and pathologic entity. Neurology 1990:40:1-8.

3 Kalra S, Bergeron C, Lang AE. Lewy body disease and dementia. A review. Arch Int Med 1996;156:487-93.

4 McKhann G, Drachman D, Folstein MF, et al. Clinical diagnosis of Alzheimer's disease: report of the NINCDS-ADRDA Work Group under the auspices of the Department of Health and Human Services Task Force on Alzheimer's disease. Neurology 1984;34:939-44

5 McKeith IG, Galasko D, Kosaka K, et al. Consensus guidelines for the clinical and pathologic diagnosis of dementia with Lewy bodies (DLB): report of the consortium on DLB international workshop. Neurology 1996:47: $1113-24$

6 Mega MS, Masterman DL, Benson DF, et al. Dementia with Lewy bodies: reliability and validity of clinical and pathologic criteria. Neurology 1996;47:1403-9.

7 Papka M, Rubio A, Schiffer RB, et al. Lewy body disease: can we diagnose it? J Neuropsychiatry Clin Neurosci 1998;10:405-12.

8 Holmes C, Cairns N, Lantos PL, et al. Validity of current clinical criteria for Alzheimer's disease, vascular dementia and dementia with Lewy bodies. Br J Psychiatry 1999;174:45-50.

9 Lopez OL, Litvan I, Catt KE, et al. Accuracy of four clinical diagnostic criteria for the diagnosis of neurodegenerative dementias. Neurology 1999;53:1292-9.

10 Verghese J, Crystal HA, Dickson DW, et al. Validity of clinical criteria for the diagnosis of dementia with Lewy bodies. Neurology 1999;53:1974-182

11 Luis CA, Barker WW, Gajaraj K, et al. Sensitivity and specificity of three clinical criteria for dementia with Lewy bodies in an autopsy-verified sample. Int J Geriatr Psychiatry 1999;14:526-33.

12 Gomez-Isla T, Growdon WB, McNamara M, et al. Clinicopathologic correlates in temporal cortex in dementia with Lewy bodies. Neurology 1999;53:2003-9.

13 McKeith IG, Ballard CG, Perry RH, et al. Prospective validation of consensus criteria for the diagnosis of dementia with Lewy bodies. Neurology 2000;54:1050-8.

14 Kukull WA, Larson EB, Reifler BV, et al. The validity of 3 clinical diagnostic criteria for Alzheimer's disease. Neurology 1990;40: 1364-9.

15 Burns A, Luthert $P$, Levy $R$, et al. Accuracy of clinical diagnosis of Alzheimer's disease. BMU 1990;301:1026.

16 Hughes AJ, Daniel SE, Kilford L, et al. Accuracy of clinical diagnosis of idiopathic Parkinson's disease: a clinico-pathological study of 100 cases. J Neurol Neurosurg Psychiatry 1992;55:181-4

17 Ballard C, Holmes C, McKeith I, et al. Psychiatric morbidity in dementia with Lewy bodies: a prospective clinical and neuropathological comparative study with Alzheimer's disease. Am J Psychiatry 1999; 156:1039-45

18 McKeith I, Del Ser T, Spano P, et al. Efficacy of rivastigmine in dementia with Lewy bodies: a randomised, double-blind, placebo-controlled international study. Lancet 2000;356:2031-6.
19 Piggott MA Marshall EF, Thomas N, et al. Striatal dopaminergic markers in dementia with Lewy bodies, Alzheimer's and Parkinson's disease; rostro-caudal distribution. Brain 1999;122:1449-68.

20 Ichise M, Kim YJ, Ballinger JR, et al. SPECT imaging of pre- and postsynaptic dopaminergic alterations in L-dopa-untreated PD. Neurology 1999:52:1206-14.

21 Kim SE, Lee WY, Choe YS, et al. SPECT measurement of iodine-123-beta-CIT binding to dopamine and serotonin transporters in Parkinson's disease: correlation with symptom severity. Neurol Res 1999;21:255-61

22 Asenbaum S, Pirker W, Angelberger $\mathrm{P}$, et al. ${ }^{123}$ lbeta-CIT and SPECT in essential tremor and Parkinson's disease. J Neural Transm 1998;105:1213-28.

23 Tissingh G, Bergmans P, Booij J, et al. Drug-naive patients with Parkinson's disease in Hoehn and Yahr stages I and II show a bilateral decrease in striatal dopamine transporters as revealed by ${ }^{123}$ |beta-CIT SPECT. J Neurol 1998;245: 14-20.

24 Wenning GK, Donnemiller E, Granata R, et al. ${ }^{123} \mathrm{l}$-beta-CIT and ${ }^{123}$ I-IBZM-SPECT scanning in levodopa-naive Parkinson's disease. Mov Disord 1998;13:438-45.

25 Muller T, Farahati J, Kuhn W, et al. ${ }^{123}$ lbeta-CIT SPECT visualizes dopamine transporter loss in de novo parkinsonian patients. Eur Neurol 1998:39:44-8.

26 Muller T, Eising E, Kuhn W, et al. Delayed motor response correlates with striatal degeneration in Parkinson's disease. Acta Neurol Scand 1999; 100:227-30.

27 Seibyl JP, Marek KL, Quinlan D, et al. Decreased single-photon emission computed tomographic ${ }^{123}$ beta-CIT striatal uptake correlates with symptom severity in Parkinson's disease. Ann Neurol 1995;38:589-98.

28 Marek KL, Seibyl JP, Zoghbi SS, et al. ${ }^{123}$ lbeta-CIT/SPECT imaging demonstrates bilateral loss of dopamine transporters in hemi-Parkinson's disease. Neurology 1996:46:231-7.

29 Brucke T, Asenbaum S, Pirker W, et al. Measurement of the dopaminergic degeneration in Parkinson's disease with ${ }^{123} \mathrm{lbeta}-\mathrm{CIT}$ and SPECT. Correlation with clinical findings and comparison with multiple system atrophy and progressive supranuclear palsy. J Neural Transm Suppl 1997;50:9-24.

30 Donnemiller E, Heilmann J, Wenning GK, et al. Brain perfusion scintigraphy with $99 \mathrm{mTc}-\mathrm{HMPAO}$ or $99 \mathrm{mTc}-\mathrm{ECD}$ and ${ }^{123}$-beta-CIT single-photon emission tomography in dementia of the Alzheimer-type and diffuse Lewy body disease. Eur J Nucl Med 1997;24:320-5.

31 Laruelle $M$, Wallace E, Seibyl JP, et al. Graphical, kinetic, and equilibrium analyses of in vivo ${ }^{123}$ beta-CIT binding to dopamine transporters in healthy human subjects. J Cereb Blood Flow Metab 1994:14:982-94.

32 Booij J, Tissingh G, Boer GJ, AG et al. ${ }^{123}$ IFP-CIT SPECT shows a pronounced decline of striatal dopamine transporter labelling in early and advanced Parkinson's disease. J Neurol Neurosurg Psychiatry 1997:62:133-40

33 Tissingh G, Booij J, Bergmans $P$, et al. lodine-123-N-omega-fluoropropyl-2 beta-carbomethoxy-3beta-14-iod ophenyl)tropane SPECT in healthy controls and early-stage, drug-naive Parkinson's disease. J Nucl Med 1998;39:1 143-8.

34 Benamer TS, Patterson J, Grosset DG, et al. Accurate differentiation of parkinsonism and essential tremor using visual assessment of ${ }^{123}$-FP-CIT SPECT imaging: the ${ }^{123} \mathrm{I}-\mathrm{FP}-\mathrm{CIT}$ study group. Mov Disord 2000; 15:503-10

35 Folstein MF, Folstein SE, McHugh PR. "Mini-Mental State": a practical method for grading the cognitive state of patients for the clinician. $J$ Psychiatr Res 1975;12:189-98.

36 Roth M, Tym E, Mountioy CQ, et al. CAMDEX: a standardised instrument for the diagnosis of mental disorders in the elderly with specia reference to the early detection of dementia. Br J Psychiatry 1986;149:698-709.

37 Berl L. Clinical Dementia Rating (CDR). Psychopharmacol Bull 1988;24:637-9

38 Alexopoulos GS, Abrams RC, Young RC, et al. Cornell scale for depression in dementia. Biol Psychiatry 1988;23:271-84.

39 Reisberg B, Borenstein J, Salob SP, et al. Behavioural symptoms in Alzheimer's disease: phenomenology and treatment. J Clin Psychiatry 1987;48(suppl):9-15.

40 Langston JW, Widner H, Goetz CG, et al. Core assessment program for intracerebral transplantations (CAPIT). Mov Disord 1992;7:2-13.

41 Hoehn MM, Yahr MD. Parkinsonism: onset, progression and mortality Neurology 1967;17:427-42.

42 Pattie AH, Gilleard CJ. Clifton assessment procedures for the elderly (CAPE): behaviour rating scale. Sevenoaks: Hodder and Stoughton Educational, 1979.

43 Hu XS, Okamura N, Arai H, et al. ${ }^{18} \mathrm{~F}$-fluorodopa PET study of striatal dopamine uptake in the diagnosis of dementia with Lewy bodies. Neurology 2000;55: 1575-7.

44 Langlais PJ, Thal L, Hansen L, et al. Neurotransmitters in basal ganglia and cortex of Alzheimer's disease with and without Lewy bodies. Neurology 1993;43:1927-34.

45 Lavalaye J, Booii J, Reneman L, et al. Effect of age and gender on dopamine transporter imaging with ${ }^{123}$ IFP-CIT SPET in healthy volunteers. Eur J Nucl Med 2000;27:867-9.

46 Walker Z, Costa DC, Janssen AG, et al. Dementia with Lewy bodies: a study of post-synaptic dopaminergic receptors with ${ }^{123}$ IIBZM SPET. Eur J Nucl Med 1997;24:609-14. 